\title{
Spectacle frames: Disposal practices, biodegradability and biocompatibility - A pilot study
}

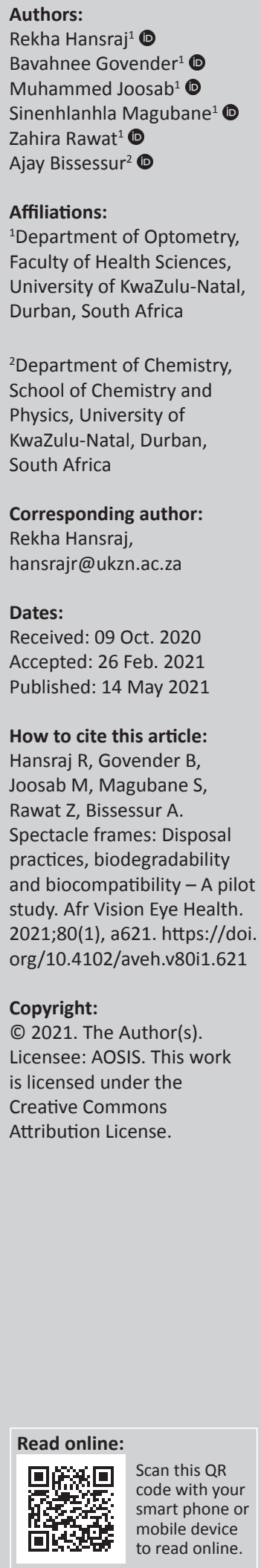

Background: Only limited information is available on the disposal methods for spectacle frames, and their interaction with the environment once such disposal occurs.

Aim: This study investigates the disposal of spectacle frames and provides a preliminary report on their biodegradability and biocompatibility.

Setting: The study was conducted at a university in the south eastern part of South Africa.

Methods: The study was conducted in two parts: Part A consisted of an explorative, quantitative design using a closed-ended questionnaire investigating the current disposal methods of 375 spectacle wearers for their old spectacles; and Part B consisted of a descriptive, cross-sectional design involving chemical analyses of metal and plastic spectacle frames.

Results: Almost 55\% of the participants reported either keeping or reusing their spectacles. Only $5 \%$ had used a recycling method when disposing their previous spectacles. Inductively coupled plasma optical emission spectroscopy results showed that metal frames do not degrade easily unless they are oxidised in an acidic environment. Lead was detected in two metal frames. Results of thermogravimetric analysis revealed that plastic frames only begin to degrade at temperatures over $250^{\circ} \mathrm{C}$. Gas chromatography-mass spectrometry results suggest that plastic frames, except three dimensional (3-D) polarisers, are biocompatible as they are stable, not chlorinated and do not possess heavy metals. The results suggested that ecofriendly frames may be the most biocompatible.

Conclusion: It appears that few spectacle wearers use recycling for disposing their frames. Current metal and plastic spectacle frames appear to have poor biodegradability but good biocompatibility.

Keywords: biocompatibility; biodegradability; disposal practices; eco-friendly spectacle frames; gas chromatography; spectacle frames; spectroscopy.

\section{Introduction}

The materials used in a day-to-day living account for $58 \%-70 \%$ of the total waste generated, with most of it finding its way to landfills. ${ }^{1}$ In the environment, these materials can be biodegradable, meaning that the material is capable of being decomposed by bacteria or living organisms, ${ }^{2}$ and/or biocompatible which implies that the material interacts with a living system without causing harm to it. ${ }^{3}$ Non-biodegradable materials such as plastic and those that are non-biocompatible are hazardous to the environment. In addition, the decomposition of these materials can result in the emission of greenhouse gases into the atmosphere, ${ }_{1}^{1}$ often because of inappropriate disposal practices, consequently causing climate change. ${ }^{4}$

Appropriate waste management is expected to positively impact on climate change by reducing landfill methane emissions amongst other things, ${ }^{5}$ therefore, proving that the decomposition behaviour of everyday materials is vital. An example of an everyday device used by many people is spectacles. The corrective lenses are held in place by spectacle frames, which are often made of plastic and/or metal resulting in them constituting various chemical compounds. Plastic frames may be constructed using materials such as cellulose acetate, cellulose propionate, epoxy resin, carbon fibre, optyl, polyamide $\mathrm{X}$, nylon and zylonite, whereas metal frames are constructed using titanium, nickel, aluminium, gold, Monel (nickel alloy of nickel and copper, with smaller amounts of iron, manganese, carbon and silicon) and stainless steel. ${ }^{6}$

Some of these materials may contain heavy metals which are naturally occurring elements with high atomic weights and much denser than water. Examples include lead, 
mercury and chromium. They are regarded as toxic to human organs and also postulated to be carcinogenic. ${ }^{78}$ Others, like copper, iron and zinc, may be regarded as essential elements as they play an important role in the biochemical and physiological functions in plants and animals, including humans with their absence possibly resulting in disease. ${ }^{9}$ However, these essential elements can also become toxic if taken in excessive amounts. Nickel and silver have no known biological functions and are, therefore, classified as non-essential elements but may create allergies. ${ }^{9,10}$

A literature search revealed only one study that reported the biocompatibility of titanium used as a material for spectacles frames. ${ }^{11}$ No other studies have been conducted, to the best of the researchers' knowledge, on either the biodegradability or biocompatibility of spectacles frames or the methods of their disposal.

More recently the health-care industry has been increasingly under the spotlight for contributing to climate change and global warming, ${ }^{12}$ and initiatives are now being encouraged to reduce its ecological footprint by looking for 'greener' solutions. ${ }^{13}$ Alternate materials for spectacle frames including buffalo horn, bamboo, seaweed and human hair have been used more recently. ${ }^{14}$ Whilst these materials are known to be environmental friendly, the disadvantages of alternate materials include cost and maintenance together with the lack of studies on their durability.

Spectacle wearers are often encouraged to have an eye test every 18-24 months to assess and, if required, renew their spectacle prescription, which may involve the purchase of a new spectacle frame. No published statistics were found on the number of spectacle wearers in South Africa, let alone the world; however, it was estimated that in 2017, an average of $48.34 \%$ of individuals in Europe were spectacle wearers. ${ }^{15}$ This is a significant number of spectacle frames out in circulation, which will require disposal and probably end up in landfill sites particularly as land filling is the most common method of waste disposal worldwide for both organic and inorganic waste. ${ }^{16}$ A possible alternative to this could be collection of old spectacles by optometric practices and distribution of relevant ones to organisations that may consider reusing them, with the remainder directed to disposal companies utilising environmentally friendly disposal practices. Organic waste that include plant and animal matter are often biodegradable. Inorganic waste, on the other hand, which often include products made of plastic, do not disintegrate or take a very long time to disintegrate. As a significant number of the world's population is expected to be spectacle wearers, it is important to determine how biodegradable and/or biocompatibility of spectacle frames. The aim of the present study, therefore, was to explore the current disposal methods for spectacle frames in Durban, South Africa, and to provide a preliminary report on their biodegradability and biocompatibility.

\section{Material and methods}

The study was conducted in two parts and the methods undertaken for each part are separately described below.

\section{Part A}

Part A involved a questionnaire survey of a purposive sample of 375 spectacle wearers from an university in the south eastern part of South Africa, who were 18 years and older, of any race and either gender to establish the current disposal methods of spectacle frames. First-time spectacle wearers, wearers of only sunglasses and those using ecofriendly frames were excluded from the study. This part of the study employed a quantitative and exploratory research design, and the data collection instrument was a questionnaire that probed demographics, previous spectacle characteristics and disposal methods. The questionnaire consisted of closedended questions. A pilot study was conducted on a total of six university staff and students with minor modifications required to the questionnaire prior to the use in the main study. The questionnaire was administered by one of the researchers once the informed consent had been given, and approximately $5 \mathrm{~min}$ were required for completion.

\section{Part B}

Part B comprised the chemical analysis of spectacle frames. This part of the study employed an exploratory and descriptive research design. The study population included spectacle frames categorised by four price ranges as shown in Table 2, including eco-friendly frames and frames one could purchase at a flea market. To obtain the spectacle frames, a list of all 147 optometrists within a $20-\mathrm{km}$ radius of the central business district (CBD) was compiled. The list was in alphabetical order and each optometrist was numbered. Thereafter, a table of random numbers was used for the selection of five optometrists, one per four retail price categories specified in Tables 2, 3 and 4 (in South African Rands [R]), from whom the spectacle frames (one plastic and one metal) were requested to be donated to the study. One plastic and one metal frame were purchased from a flea market in the CBD. A pair of three dimensional (3-D) polarisers (plastic frame) distributed at a local cinema was also included in the sample. Thus, a total of 12 frames, namely, 5 plastic, 5 metal, 1 eco-friendly (plastic) and 1 plastic polariser were included in the study. Once received, the spectacle frames were numbered before undergoing chemical analysis under the guidance and supervision of the Chemistry Department of the University. Frames were broken down to remove the nose pads, temple tips and screws. The remainder of the frame was weighed and recorded.

Then the spectacle frames underwent a limited number of tests because of time constraints. Metal frames underwent chemical characterisation using inductively coupled plasma optical emission spectroscopy (ICPOS) to identify heavy metals in the frame material. ${ }^{17}$ Heavy metals considered 
particularly hazardous for the environment include lead, cadmium arsenic and mercury. Plastic frames were exposed to thermogravimetric analysis (TGA) to determine the types of gases emitted in the ageing process, ${ }^{18}$ and gas chromatography-mass spectrometry (GC-MS) which was used to identify components, particularly, impurities, such as halogenated polymers in the spectacle material. ${ }^{19}$

The data obtained were captured using the Statistical Package for Social Sciences version 23 and reported using descriptive statistics.

\section{Ethical considerations}

Ethical clearance for this study was obtained from the School of Health Sciences Ethics Committee (SHSEC 023/15), University of KwaZulu-Natal. The study adhered to the tenets of the Declaration of Helsinki, and informed consent was obtained from all participants in Part A of the study.

TABLE 1: Characteristics of spectacle usage among participants.

\begin{tabular}{lc}
\hline Variable & Percentage \\
\hline Duration of spectable usage & 24.0 \\
2-3 year & 26.0 \\
$4-5$ years & 50.0 \\
6 year and more & \\
Material of previous spectacle frame & 46.9 \\
Plastic & 26.9 \\
Metal & 26.2 \\
Combination & \\
Frequency of spectacle frame replacement & 70.7 \\
1-2 years & 24.8 \\
3-4 years & 4.5 \\
5 years and longer &
\end{tabular}

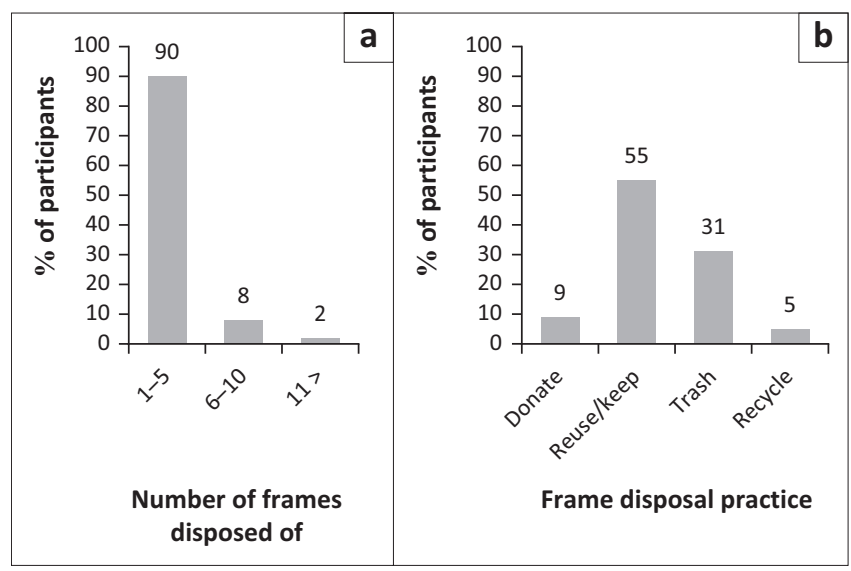

FIGURE 1: Disposal practices for used spectacle frame(s) per participant as determined in the questionnaire survey (a) Number of frames disposed of, (b) Frame disposal practice.

\section{Results}

\section{Part A}

Three hundred and seventy-five spectacle wearers of mean age 20.67 years participated in the survey with the majority $(66 \%)$ being female. The sample included all races but the majority were Indians (72\%), followed by black people $(25 \%)$, white people $(2 \%)$ and $1 \%$ of participants were of mixed race. The characteristics of spectacle usage amongst the respondents are outlined in Table 1.

Figure 1 shows that $90 \%$ of the participants had already disposed of between one and five spectacles throughout their lives, with the majority (55\%) retaining them for possible reuse. Only $5 \%$ of participants had considered recycling their previous pair(s). Many of the participants were unaware of the availability of eco-friendly frames, and when informed about them, 87\% encouragingly reported that they would consider them.

In Figure 1, the first section shows the number of spectacles frames that may have been disposed thus far. The method of disposal is illustrated in the second section. Bars with numbers are representative of the percentages (\%) of participants.

\section{Part B}

The results from chemical analysis are presented separately for metal and plastic frames.

\section{Metal frames}

The concentration $(\mathrm{mg} / \mathrm{g}$ ) of the main elements isolated from the metal frames using ICPOS is illustrated in Table 2. Lead was the only toxic element detected in two metal frames, with the highest concentration being in the spectacle frame purchased at the flea market. The essential elements manganese, iron, copper and chromium were found in all frames whilst zinc was not detected in frames that cost over R1000.00 Both iron and copper were found in the highest concentration in all frames.

\section{Plastic frames}

Thermogravimetric analysis was used to investigate the thermal decomposition of plastic frames in terms of the percentage mass loss (represented by percentage mass transfer) in relation to the temperature at which this occurred and the results are shown in Table 3. The lowest temperature at which any of the frames first started to decompose was $285.8^{\circ} \mathrm{C}$ and the highest temperature was $492.5^{\circ} \mathrm{C}$. In those frames in which a second degradation occurred, the temperature was greater than $360^{\circ} \mathrm{C}$. At a

TABLE 2: Concentration ( $\mathrm{mg} / \mathrm{g}$ ) of main elements isolated from metal frames using inductively coupled plasma optical emission spectroscopy.

\begin{tabular}{|c|c|c|c|c|c|c|c|c|}
\hline Variable & Lead $(\mathrm{Pb})$ & Zinc (Zn) & Manganese (Mn) & Iron (Fe) & Copper (Cu) & Chromium (Cr) & Silver (Ag) & Nickel (Ni) \\
\hline Flea market & 1.45 & 163.14 & 1.71 & 388.56 & 311.62 & 0.47 & ND & 3.20 \\
\hline R1.00-R500.00 & ND & 82.00 & 10.21 & 76.24 & 243.45 & 20.93 & 0.90 & 32.29 \\
\hline R501.00-R1000.00 & 0.188 & 125.84 & 5.07 & 82.38 & 486.53 & 28.05 & 0.60 & 170.66 \\
\hline R1001.00-R2000.00 & ND & ND & 11.29 & 403.30 & 263.72 & 142.11 & 1.61 & 184.23 \\
\hline$>$ R2000.00 & ND & ND & 5.02 & 184.77 & 53.22 & 61.80 & 0.577 & 93.86 \\
\hline
\end{tabular}

ND, not detected. 
TABLE 3: Thermal decomposition of plastic frames using thermogravimetric analysis versus price categories.

\begin{tabular}{|c|c|c|c|c|c|}
\hline \multirow[t]{2}{*}{ Sample } & \multicolumn{2}{|c|}{ 1st degradation } & \multicolumn{2}{|c|}{ 2nd degradation } & \multirow{2}{*}{$\frac{\text { Total } \% \text { mass degraded }}{\text { At } 700{ }^{\circ} \mathrm{C}}$} \\
\hline & $\%$ Mass transfer & Temp. $\left({ }^{\circ} \mathrm{C}\right)$ & $\%$ Mass transfer & Temp. $\left({ }^{\circ} \mathrm{C}\right)$ & \\
\hline Flea market & 21.00 & $492.5 \uparrow$ & - & - & 21.00 \\
\hline R1.00-R500.00 & 15.00 & 299.0 & 47.0 & 375.0 & 62.00 \\
\hline R501.00-1000.00 & 20.00 & 293.0 & 40.7 & 361.0 & 60.70 \\
\hline R1001.00-R2000.00 & 51.70 & 364.4 & - & - & 51.70 \\
\hline$>$ R2000.00 & 17.50 & $285.8 \downarrow$ & 41.8 & 385.7 & 59.30 \\
\hline Eco friendly & 4.17 & 295.0 & 57.5 & 364.3 & 61.67 \\
\hline 3D polarizers & 46.00 & 428.6 & - & - & 46.00 \\
\hline
\end{tabular}

Temp, temperature; 3-D, three dimensional; Eco, environment friendly.

TABLE 4: Properties of organic compounds identified with gas chromatographymass spectrometry.

\begin{tabular}{lccc}
\hline Variable & $\begin{array}{c}\text { Retention Time } \\
\text { (min) }\end{array}$ & $\begin{array}{c}\text { Molecular weight } \\
\text { (g/mol) }\end{array}$ & $\begin{array}{c}\text { Carbon chain length } \\
\text { (no. of carbons) }\end{array}$ \\
\hline Flea market & 4.394 & 116 & 6 \\
R1.00-R500.00 & 15.124 & 222 & 12 \\
R501.00-1000.00 & 15.158 & 222 & 12 \\
R1001.00-R2000.00 & 23.603 & Unidentified & Unidentified \\
> R2000.00 & 15.111 & 164 & 9 \\
Eco-friendly & 15.115 & 164 & 9 \\
3-D polarisers & $4.382-25.261 \dagger$ & $100-208 \dagger$ & $6-14 \dagger$ \\
\hline
\end{tabular}

Eco, environment friendly; $3-D$, three dimensional.

$\dagger$, Eight organic compounds released.

maximum of $700{ }^{\circ} \mathrm{C}$, an average of $55 \%$ of the total mass of the frames of all price ranges had degraded, with the exception of the flea market frame. Only $21 \%$ of the flea market frame had broken down at $700{ }^{\circ} \mathrm{C}$.

The GC-MS test investigated the properties of the organic compounds released from a material, which included the retention time which is the time taken for that compound to be released, the molecular weight $(\mathrm{g} / \mathrm{mol})$ and carbon chain length (number of carbons) (Table 4).

Similar retention times of approximately $15 \mathrm{~min}$ were found for most of the frames, other than the flea market frame $(4.39 \mathrm{~min})$ and the $3-\mathrm{D}$ polarisers $(4.38-25.26 \mathrm{~min})$. The molecular weight of the compounds released ranged from $100 \mathrm{~g} / \mathrm{mol}$ to $222 \mathrm{~g} / \mathrm{mol}$ and the carbon chain lengths from 6 to 14 carbons per chain. The plastic frame purchased at the flea market had the second lowest retention time, a fairly low molecular weight and the smallest carbon chain length. The most expensive frame had a relatively lower retention time, molecular weight and carbon chain length compared to the slightly cheaper frames. With the exception of the 3-D polarisers from which eight organic compounds of varying molecular weights and chain lengths were released, only one organic compound was released from each of the other plastic frames.

\section{Discussion}

Currently wide-scale interest exists in the generation of waste products by human beings and their disposal practices particularly because of its contribution to global warming. This has led to a considerable focus on recycling initiatives with the aim of conserving energy, reducing pollution and reducing waste in landfills. Spectacle wearers do not appear to use this method of disposal as only $5 \%$ of the participants in this study had chosen to recycle their previous spectacles. The remaining 95\% donate, reuse or trash their old spectacles, and it can be assumed that many of these will eventually end up in a landfill. Furthermore, considering that the mean age of the participants was only 20.67 years and assuming an average life expectancy of 64 years in the South African population, ${ }^{20}$ approximately 20 more pairs per spectacle wearer can be expected to be disposed of as most participants reported replacing their spectacle frames every 1-2 years. The implication of this is that just in a single province in South Africa, there are a large amount of spectacle frames in circulation that could make their way to landfills if alternate methods of disposal are not considered.

Almost one-third of the participants (26.9\%) were using metal spectacle frames. The biodegradability and biocompatibility of the metal frames were assessed in terms of the elements contained in the frames. The main elements extracted from the metal frames (listed in Table 1) fell into the classes of heavy metals, essential metals and non-essential metals. Heavy metals are those that are poisonous even at lower levels of exposure, as well as carcinogenic, and include lead, chromium, cadmium and mercury. ${ }^{21}$ Lead was found in two of the metal frames with the highest concentration found in the frame obtained at the flea market. The other one was a frame that fell into the price category of R501.00 - R1000.00 that was considered as a medium cost frame. Lead is used in the manufacture of spectacle frames as it adds lustre to frames and makes them resistant to corrosion; however, it is associated with birth defects and delayed development. ${ }^{22}$ Furthermore, of all the heavy metals, lead has been known to pose the greatest threat to male fertility by reducing sperm count. ${ }^{23}$ If disposed of in a landfill, the element is expected to leach into the soil and following rain can be washed away to areas other than the landfill sites. Lead in soil can lead to an increase in blood concentration of lead particularly in children playing with soil. ${ }^{24}$

Another heavy metal, chromium was found in all the frames, including the eco-friendly ones. Chromium is used for plating frames and it can also be used in some alloys for the underlying base material, with metal processing known to be one of the largest contributors to chromium release. ${ }^{21}$ They can also be used to obtain a black surface on copper-nickel spectacle frames. ${ }^{25}$ The main route of exposure to chromium is via inhalation ${ }^{26}$ but also through the ingestion of food or water containing chromium ${ }^{27}$ that exposes all living entities to this toxic element. Chromium and lead are regarded as 
priority metals because of their high toxicity and are said to be of significant public concern. ${ }^{21}$

The other elements isolated from the metal frames included zinc, manganese, iron, copper with iron and copper having the highest concentration in all frames. These elements are regarded as essential metals necessary for biochemical and physiological functions and their absence can result in diseases. ${ }^{9}$ On the other hand, an excess amount can result in tissue damage; and for copper and chromium, the range between beneficial and toxic is very narrow. ${ }^{7,8}$ In the worstcase scenario, iron can release arsenate into the environment and cause damage to the aquatic life.

Relatively lower amounts of nickel and even lower amounts of silver were detected in the sample, which may be expected as technical frames do not actually contain any silver. Nickel and silver are regarded as non-essential elements as they have no known biological functions. ${ }^{7}$ Nickel is strong and pliable, but the disadvantages of nickel are that about $10 \%$ of the population may be allergic to it. ${ }^{10}$ Therefore, nickel is seldom used in its pure form in spectacle frames except when used for plating to improve the adherence of outer layers of other frames. ${ }^{10}$ Silver has also been known to damage the organs of aquatic life.

Iron and copper were found in the highest concentrations in this study. It is, therefore, important to note that most metals do not degrade in nature easily unless they are dissolved or oxidised in an acidic environment and may, therefore, take years to disintegrate. However, different soil environments can accelerate their degradation. ${ }^{28}$ Iron rusts caused by exposure to oxygen, with rust actually being an iron oxide. Metals like magnesium, aluminium, gold and platinum that are also used in the manufacture of metal frames are not at all biodegradable and fortunately were not found in the frame sample for this study. Overall, metal frames can be considered as having poor biodegradability with the implication that they can, therefore, remain as solid waste in the environment for a long time; however, this property also prevents certain toxic elements from being released into the environment too quickly. Considering that whilst metal frames contain toxic metals, they contain a greater concentration of essential elements like zinc and manganese found in the current, they are therefore more biocompatible than not. Overall, the eco-friendly frame, included in this study, had the lowest concentration of all elements, implying that they might be the most biocompatible. Just an observation, no correlation was found between the concentration of elements in each frame and its price range; therefore, the cost of frames seems to be a matter of branding.

Thermogravimetric analysis was used to investigate the biodegradability of plastic frames. This test determined the thermal decomposition of plastic frames in terms of the mass loss represented by the percentage of mass transfer in relation to the temperature at which this occurred.

The higher the degradation temperature, the more stable the plastic material but implies poor degradation.
The lowest temperature at which any of the plastic frames first started to degrade was $285.8^{\circ} \mathrm{C}$. The highest air temperature ever recorded was $56.7^{\circ} \mathrm{C}$ in 1913 in California and a higher surface temperature of $70.7^{\circ} \mathrm{C}$ was recorded in Iran in 2004/2005. ${ }^{29}$ Even soil temperature will not get to as high as $285.5^{\circ} \mathrm{C} .{ }^{30}$ Cellulose acetate is one of the more common materials used for the production of spectacle frames ${ }^{31}$ because of its transparency and texture. ${ }^{32}$ Cellulose acetate degrades very slowly ${ }^{32}$; and whilst it can be biodegraded by certain organisms, they first require deacetylation, which cannot occur naturally in the environment. ${ }^{33}$ Furthermore, they also have limited photo degradability. ${ }^{33}$ The advantage of poor biodegradability is that toxic elements are not immediately released, whilst the disadvantage is that they persist as solid waste in the environment.

Biocompatibility of plastic frames was studied using GCMS. This test investigates the properties of the organic compounds released when a material is broken down, including the retention time which is the time taken for that carbon compound to be released, the molecular weight and carbon chain length of the compound released. The higher the retention time, molecular weight and the carbon chain length, the greater the stability of that compound. ${ }^{34}$ Only the formula of each compound could be identified as no reference list of materials was available. Therefore, the exact compound released could not be identified. Based on this analysis, the cheaper frames appeared to produce carbon compounds that were more stable, indicating that pricing is not an indication of biocompatibility. The eco-friendly frame did not appear to be as stable with respect to the release of carbon compounds compared to the other frames; and, therefore, their current classification as eco-friendly frames should be reviewed. With the advent of 3-D movies, a large number of 3-D polarisers are in circulation. They are purchased at a very nominal price and disposal is left to the purchaser. With the chemical analysis, they appear to be made of a material that releases a large number of carbon compounds when broken down. Carbon compounds are fairly stable and less susceptible to attack in the soil and, therefore, persist longer before degrading. They are not chlorinated and have no heavy metals, and, therefore, they can actually enrich the soil for plant growth; however, too much of carbon in the soil will diminish this effect. Furthermore, carbon released into the atmosphere contributes to greenhouse gases and thereby global warming, whilst carbon in the ocean leads to a more acidic environment that may pose danger to aquatic life.

After use, the majority of spectacle frames end up in the waste and awareness should be created about the possibility of disposing spectacles into recycling waste. This study found that both metal and plastic spectacle frames have poor biodegradability but good biocompatibility. Therefore, whilst they may not be immediately hazardous to the environment, they contribute to solid waste in landfills. Frames purchased to be distributed at flea markets should be reviewed for 
material constituents and better regulated as the material currently being used appears to contain elements toxic to the environment, and the frame material does not appear to be stable. The 3-D polarisers currently being distributed at cinemas need to be further analysed and, considering their wide-scale use, need to be reviewed in terms of alternative materials for their production because the current material exhibits poor degradation and instability with respect to carbon compounds. Distributors of these 3-D polarisers should also consider offering environmental-friendly disposal methods. Testing of spectacle frames made from alternative materials like bamboo and hair needs to be carried out in terms of their stability and durability, so that they can be suggested to patients.

Biodegradability refers more specifically to the ability of organisms to breakdown a material and although one of the more ideal tests would be a soil test; however, the tests used in this study do indirectly give an indication of this aspect. Limitations of the current study include the testing of a relatively small selection of frames because of time and financial constraints; and, thus, a larger scale study could provide more useful information. Another limitation is that only frames were analysed in this study and not the nose pads and temple tips which are important as they are of plastic material. The sponsored eco-friendly frame had no endorsement. The organic compounds released from plastic frames could not be identified, as the reference lists of spectacle material components from manufacturers were not available at the time of testing, and the study was restricted to a laboratory investigation.

It is recommended that an investigation of the biodegradability and biocompatibility of other optical devices, including sunglasses, and/or their components such as the lenses, temple tips, nose pads and alternate frame materials as well as contact lenses, should be carried out in the future studies. Spectacles such as ready-made readers such as those sold in pharmacies should also be investigated. A larger sample of frames per price category should be considered to acquire a mean result per frame. A longitudinal study is advised in a natural environment as opposed to a laboratory-based study to obtain more realistic results and biodegradability in its true sense. Optometrists must be made aware of the use of alternate frame materials as well as consideration of discarding old pairs into recycling waste. Patients should be made aware of ecofriendly alternatives as many consumers are unaware of their existence. Spectacle disposal initiatives that redirect waste to disposal companies should be made by optometric practices to encourage proper disposal of spectacles, thereby reducing their carbon footprint. Manufacturers of metal spectacle frames should find alternate elements to replace heavy metals such as lead and be educated on the dangers of toxic elements. Despite the limitations, this study provides useful information and paves the way for more detailed investigations, which can have monumental impact on reducing the carbon footprint of spectacle frames.

\section{Acknowledgements}

The authors acknowledge the assistance and contribution of Ms Zanele Ximba and Ms Felicia Naidu to this study. The authors acknowledge that the idea for this study was obtained from Mr PK Govender and to whom the authors are grateful.

\section{Competing interests}

The authors declare that they have no financial or personal relationships that may have inappropriately influenced them in writing this article.

\section{Authors' contributions}

R.H., B.G., M.J., S.J., Z.R. and A.B. were involved in the conceptualisation of this study and the compilation of the research paper. B.G., M.J., S.M. and Z.R. were involved in the data collection as well.

\section{Funding information}

This research received no specific grant from any funding agency in the public, commercial or not-for-profit sectors.

\section{Data availability}

The data that support the findings of this study are available from the corresponding author, [R.H.], upon reasonable request.

\section{Disclaimer}

The views and opinions expressed in this article are those of the authors and do not necessarily reflect the official policy or position of any affiliated agency of the authors.

\section{References}

1. Secretariat of the Pacific Regional Environment Programme (SPREP). Factsheet No PYCC-004: Waste and climate change [homepage on the Internet]. 2009 [cited 2018 Aug 6]. Available from: https://www.sprep.org/climate_change/PYCC/ documents/ccwaste.pdf

2. Chait J. What 'Biodegradable' really means. Sustainable businesses: Organics glossary 2019 [homepage on the Internet]. 2019 [cited 2018 Aug 6]. Available from: https://www.thebalancesmb.com/what-does-biodegradable-mean-2538213

3. Merriam-Webster Dictionary. Definition of 'biocompatibility' 1828 [homepage on the Internet]. 2018 [cited 2018 Aug 6]. Available from: https://www.merriamwebster.com/dictionary/biocompatibility

4. Lackner KS, Jospe C. Climate change is a waste management problem. Issue Sci Technol [serial online]. 2017 [cited 2018 Aug 6];XXXIII(3). Available from: https:// issues.org/climate-change-is-a-waste-management-problem/

5. Ackerman F. Waste management and climate change. Int J Justice Sustain 2010;5(2):223-229. https://doi.org/10.1080/13549830050009373

6. Morgan S. Complete optometric assistant. Edinburgh: Butterworth-Heinemann; 2008.

7. Chang LW, Clarkson T, Magos L, eds. Toxicology of metals. Boca Raton, FL: Lewis; 1996.

8. Tchounwou PB, Newsome C, William, J, et al. Copper-induced cytotoxicity and transcriptional activation of stress genes in human liver carcinoma cells. Met lons Biol Med. 2008;10(1):285-290.

9. World Health Organization (WHO). Trace elements in human nutrition and health [homepage on the Internet]. 1996 [cited 2018 Aug 6]. Available from: https:// www.who.int/nutrition/publications/micronutrients/9241561734/en/

10. Walsh G, Wilkonson S. Material and allergens within spectacle frames: A review. Contact Dermatitis. 2006;55(3):130-139. https://doi.org/10.1111/ j.1600-0536.2006.00791.x 
11. Nakasuji K, Okada M. New high strength titanium alloy Ti-10\% Zr for spectacle frames. Mater Sci Eng. 1996;A213(1-2):162-165. https://doi.org/10.1016/0921 5093(96)10237-9

12. Eckelman MJ, Sherman J. Environmental impacts of the U.S. health care system and effects on public health. PLoS One [serial online]. 2016 [cited 2018 Aug 6]·11. Article ID e0157014. Available from: https://journals.plos.org/plosone/ article?id=10.1371/journal. pone.0157014

13. Roundtable on Environmental Health Sciences, Research and Medicine. Board on population health and public health practice; Institute of Medicine. Public health linkages with sustainability workshop summary [homepage on the Internet]. 2013 [cited 2018 Aug 6]. Washington, DC: National Academies Press. Available from: https://www.ncbi.nlm.nih.gov/pubmed/24872987

14. Morgan E. Eyeglass frame materials [homepage on the Internet]. 2018 [cited 2018 Aug 6]. Available from: https://www.allaboutvision.com/eyeglasses/eyeglass frame_materials.htm

15. Statista. Share of individuals who were spectacles in selected European countries in 2020 [homepage on the Internet]. No date [cited 2018 Aug 6]. Available from: https://www.statista.com/statistics/711514/individuals-who-wear-spectacles-inselected-european-countries

16. Manfredi S, Tonini D, Christensen TH. Landfilling of waste: Accounting of greenhouse gases and global warming contributions. Waste Manag Res. 2009;27(8):825-836. https://doi.org/10.1177/0734242X09348529

17. Moore GL. Introduction to inductively coupled plasma atomic emission spectrometry. 1st ed. Amsterdam: Elsevier; 1989.

18. Gabbott P. Principles and applications of thermal analysis. New Delhi: Blackwell Publishing; 2008.

19. Sparkman OD, Penton Z, Kitson F. Gas chromatography and mass spectrometry: A practical guide: A practical guide. 2nd ed. Burlington MA: Academic Press; 2011.

20. CABSA. South African Life Expectancy Rise [homepage on the Internet]. No date [cited 2018 Aug 6]. Available from: http://www.cabsa.org.za/South-African-LifeExpectancy-Rise-1072017

21. Tchounwou PB, Yedjou CG, Patlolla AK, et al. Heavy metals toxicity and the environment. EXS. 2012;101(1):133-164.https://doi.org/10.1007/978-3-76438340-4 6

22. US Department of Labour, Safety and Health Topics. Toxic metals [homepage on the Internet]. [cited 2018 Aug 6]. Available from: http://www.osha.gov/SLTC/ metalsheavy/
23. Apostoli P, Kiss P, Stefano, $P$, et al. Male reproduction toxicity of lead in animals and humans. Occup Environ Med. 1998;55(6):364-374. https://doi.org/10.1136/ oem.55.6.364

24. Laidlaw MAS, Mielke HW, Filippelli GM, et al. Seasonality and children's blood lead levels: Developing a predictive model using climatic variables and blood lead data from Indianapolis, Indiana, Syracuse, New York, and New Orleans, Lousiana (USA). Environ Health Perspect. 2005;113(6):793-800. https://doi. org/10.1289/ehp.7759

25. Brooks CW, Borish I. System for ophthalmic dispensing. 3rd ed. Missouri Butterworth Heinemann Publishers; 2007.

26. Costa M. Toxicity and carcinogenicity of $\mathrm{Cr}(\mathrm{VI})$ in animal models and humans. Crit Rev Toxicol. 1997;27(5):431-442. https://doi.org/10.3109/10408449709078442

27. Langård S, Vigander T. Occurrence of lung cancer in workers producing chromium pigments. Br J Ind Med. 1983;40(1):71-74. https://doi.org/10.1136/ oem.40.1.71

28. Elias V, Fishman KL, Christopher BR, et al. Corrosion/degradation of soil reinforcements for mechanically stabilized earth walls and reinforced soil slopes [homepage on the Internet]. Technical Report 2000 [cited 2018 Aug 6] Available from: http://www.terrerinforzate.it/documenti/CORROSION DEGRADATION.pdf

29. Sharp T. What is earth's average temperature? [homepage on the Internet]. 2018 [cited 2021 Feb 16]. Available from: https://www.space.com/17816-earthtemperature.html

30. Florides GA, Kalogirou SA. Annual ground temperature measurements at various depths [homepage on the Internet]. 2004 [cited 2018 Aug 6]. Available from: https://www.scribd.com/document/364232121/Annual-Ground-TemperatureMeasurements-at-Various-depths

31. Walsh G. The products we rely on - Part 2 Spectacle frame materials. Optom Today. 2001;September 7:34-41.

32. Ach A. Biodegradable plastics based on cellulose acetate. J Macromol Sci Part A. 1983;30(9-10):733-740. https://doi.org/10.1080/10601329308021259

33. Puls J, Wilson SA, Hölter D. Degradation of cellulose acetate-based materials: A review. J Polym Environ. 2011;19(1):152-165. https://doi.org/10.1007/s10924010-0258-0

34. Carbon, Carbon Bond Length, Bond Length, Tertiary Carbon| Chemistry @ TutorVista. com. [homepage on the Internet]. 2015 [cited 2018 Aug 6]. Available from: http:// chemistry.tutorvista.com/organic-chemistry/carbon-carbon-bond-length.html 